\title{
ANALGESIC EFFECT OF TRAMADOL AND BUPRENORPHIN IN CONTINUOUS PROPOFOL ANAESTHESIA
}

\author{
Capík I. ${ }^{1}$, Nagy O. ${ }^{2}$ \\ ${ }^{1}$ Small Animal Clinic \\ ${ }^{2}$ Clinic for Ruminants \\ University of Veterinary Medicine and Pharmacy \\ Komenskeho 73, 04181 Kosice \\ The Slovak Republic \\ capik.igor@uvlf.sk
}

\section{ABSTRACT}

The objective of this study was to compare in clinical patients the analgesic effect of the centrally acting analgesics tramadol and buprenorphine in continuous intravenous anaesthesia (TIVA) with propofol. Twenty dogs undergoing prophylactic dental treatment, aged $2-7$ years, weighing 6-27 kg, were included in ASA I. and II. groups. Two groups of dogs received intravenous (IV) administration of tramadol hydrochloride $\left(2 \mathrm{mg} \cdot \mathrm{kg}^{-1}\right)$ or buprenorphine hydrochloride $\left(0.2 \mathrm{mg} . \mathrm{kg}^{-1}\right) 30$ minutes prior to sedation, provided by midazolam hydrochloride $\left(0.3 \mathrm{mg} . \mathrm{kg}^{-1}\right)$ and xylazine hydrochloride $\left(0.5 \mathrm{mg} . \mathrm{kg}^{-1}\right)$ IV.Generalanaesthesiawasinducedbypropofol $\left(2 \mathrm{mg} . \mathrm{kg}^{-1}\right)$ and maintained by a 120 minutes propofol infusion $\left(0.2 \mathrm{mg} \cdot \mathrm{kg}^{-1} \mathrm{~min}^{-1}\right)$. Oscilometric arterial blood pressure (ABP) measured in $\mathrm{mm} \mathrm{Hg}$, heart rate $(\mathrm{HR})$, respiratory rate (RR), SAT, body temperature (BT) and pain reaction elicited by haemostat forceps pressure at the digit were recorded in ten minute intervals. The tramadol group of dogs showed significantly better parameters of blood pressure $(\mathrm{P}<\mathbf{0 . 0 0 1})$, lower tendency to brady- cardia $(\mathrm{P}<0.05)$, and better respiratory rate $(\mathrm{P}<0.001)$ without negative influence to oxygen saturation. Statistically better analgesia was achieved in the tramadol group $(\mathrm{P}<\mathbf{0 . 0 0 1})$. Tramadol, in comparison with buprenorphine provided significantly better results with respect to the degree of analgesia, as well as the tendency of complications arising during anaesthesia.

Key words: analgesia; buprenorphine; dog; propofol; TIVA; tramadol

\section{INTRODUCTION}

Tramadol is marketed as a racemic mixture of both $\mathrm{R}$ and $\mathrm{S}$ stereoisomers. This is because the two isomers complement each other's analgesic activity [3]. Tramadol is a reuptake inhibitor of norepinephrine and serotonin and a weak $\mu$-opioid receptor agonist [10]. Tramadol is metabolised to O-desmethyltramadol, a significantly more potent opioid. It is thought that the effects on the central catecholaminergic pathways contribute significantly to the drug's 
analgesic effect. Tramadol is recommended for the management of chronic and acute pain of moderate to moderately sever intensity [12]. Administered intravenously (IV), its analgesic potency is the same as meperidine and onetenth that of morphine [5].

Tramadol and morphine administered preoperatively were compared with the aim to assess early postoperative pain in canine ovariohysterectomy [7]. No differences were found between the two groups with regard to: analgesia, sedation, $\mathrm{SpO}_{2}, \mathrm{pH}$ and blood gases, cardiovascular variables, glucose, catecholamine, and cortisol concentrations. Tramadol ( $\left.1 \mathrm{mg} \cdot \mathrm{kg}^{-1}\right)$, administered after the induction of anaesthesia, offered equivalent postoperative pain relief, and similar recovery times and postoperative patient controlled analgesia (PCA) morphine consumption, compared with giving morphine at $0.1 \mathrm{mg} \mathrm{kg}^{-1}$. These results also suggest that pre-surgical exposure to systemic opioid analgesia may not result in clinically significant benefits [15].

Buprenorphine is a semi-synthetic partial opioid agonist that is used: to treat opioid addiction in higher dosages, to control moderate acute pain in non-opioid-tolerant individuals in lower dosages, and to control moderate chronic pain in even smaller doses [12]. Buprenorphine has produced excellent analgesic results in broad clinical applications for cats, dogs, exotic species and laboratory animals. It provides analgesia for: the management of perioperative/ postoperative pain, painful joint injuries, fractures, tissue inflammation due to infections, tissue necrosis and trauma resulting from wounds. The amelioration of postsurgical pain has been substantiated in a variety of species [13]. A study comparing an analgesic effect of butorphanol and buprenorphine in parrots, confirmed a significantly increased threshold to electrical stimuli in the case of butorphanol. Buprenorphine at the dosage used did not change the threshold to electrical stimulus. Butorphanol provided an analgesic response in half of the birds tested. It would be expected to provide analgesia to African grey parrots in a clinical setting [9]. Buprenorphine should be used with caution in animals with: head trauma, compromised cardiovascular function, liver disease and geriatric or severely debilitated animals. A rare, but possible side effect of buprenorphine, is a slowed breathing rate in some dogs, so it should not be used to treat a dog with heart failure, head trauma or respiratory issues.

Common adverse drug reactions associated with the use of buprenorphine are similar to those of other opioids and include: nausea and vomiting, drowsiness, dizziness, headache, memory loss, cognitive and neural inhibition, perspiration, itchiness, dry mouth, miosis, orthostatic hypotension and urinary retention. Constipation and CNS effects are seen less frequently than with morphine [2]. Due to the mainly hepatic elimination, there is no risk of accumulation in patients with renal impairment [8].

The objective of this study was to compare the analgesic effect of buprenorphine and tramadol in dogs premedicated with midazolam, and xylazine IV. Induction into general anaesthesia was achieved by propofol IV and anaesthesia was maintained for 120-minutes by the infusion of propofol.

\section{MATERIALS AND METHODS}

Twenty dogs undergoing dental prophylactic treatment were used in the study and the owners were informed and agreed with the anaesthetic protocol.

Intravenous catheters were placed into v. cephalica antebrachii sinistra and dextra, one for a constant rate infusion based total intravenous anaesthesia and the second one for blood collection. In the buprenorphine group (B), analgesia was achieved by $0.02 \mathrm{mg} \cdot \mathrm{kg}^{-1}$ of buprenorphine IV, 30 minutes prior to sedation. In the tramadol group (T), tramadol in the dose of $2 \mathrm{mg}$. $\mathrm{kg}^{-1} \mathrm{IV}$ was used as an algesic the same time before sedation. All dogs were sedated using $0.3 \mathrm{mg} \cdot \mathrm{kg}^{-1}$ midazolam given intravenously, fractionated into three, two minute intervals followed by $0.5 \mathrm{mg} \cdot \mathrm{kg}^{-1}$ xylazine IV. The dogs were intubated when the degree of relaxation and reflex activity allowed this procedure. Aesthetic induction with propofol at $2 \mathrm{mg} \cdot \mathrm{kg}^{-1}$ was followed by a $120 \mathrm{~min}$ propofol infusion at $0.2 \mathrm{mg} \cdot \mathrm{kg}^{-1} \cdot \mathrm{min}^{-1}$ by an infusion system IPB 2050 (Polymed). The age of dogs ranged between $2-7$ years (4.16 1.6) with weight range of $6-27 \mathrm{~kg}(12.6 \pm 2.9)$. The dogs under examination were included into ASA I. and II. groups. They were divided into two groups ( $\mathrm{B}$ and $\mathrm{T}$ ) ten animals in each. The study was approved by the local Ethics Committee (CZ). During anaesthesia, the dogs were breathing room air.

The dogs were monitored throughout the aesthetic and recovery periods. The ambient temperature was kept at $26^{\circ} \mathrm{C}$. Arterial blood pressure (ABP), heart rate (HR), respiratory rate $(\mathrm{RR})$, saturation of hemoglobin with oxygen (\% SAT), body temperature (BT), were recorded by a Patient Monitor-9000Vet (Hamburg, DE) and pain responses were recorded in ten minute intervals. The pain was in- 
duced by intermittent haemostat pressure at the digits during one minute. In the case of the appearance of decreased depth of anaesthesia, xylazine in the dose of $0.125 \mathrm{mg} \cdot \mathrm{kg}^{-1}$ or propofol $2 \mathrm{mg} \cdot \mathrm{kg}^{-1} \mathrm{IV}$ was administered. In the case of an increased plane of anaesthesia, propofol infusion was stopped. The pain response was classified in three grades: Grade 1 - no response to the pain; Grade 2 - increased heart and respiratory rate; Grade 3 - movement. During the recovery period, the time of extubation followed the presence of the swallowing reflex, the ability to lift up the head, taking a sternal position and first walking were recorded.

Statistical analysis was based on the mean values (x) and standard deviations (SD). Means obtained for the observed parameters were statistically analysed using one way analysis of variance (ANOVA). Analyses were done using MS Excel software.

\section{RESULTS}

Comparing tramadol and buprenorphine following their IV administration, the buprenorphine group (B) produced deeper sedation seen as unstable gait and lying within 5-8 minutes following administration. Fifty percent of dogs in the B group were intubated before induction of the general anaesthesia with no or minimal tracheal irritation during the procedure. This was not seen in the tramadol (T) group of dogs. In this group, following midazolam administration, dogs experienced some degree of incoordination disappearing after xylazine applications. Dogs in the $\mathrm{T}$ group were able to intubate following propofol administration. The average values of the mean blood pressure showed significant differences between groups $(\mathrm{P}<0.001)$ with higher blood pressure in the $\mathrm{T}$ group (Tab. 1). The heart rate did not differ significantly between the groups (Tab. 2).

Table 1. Changes in the mean blood pressure in the groups of dogs (mean \pm SD)

\begin{tabular}{|c|c|c|c|c|c|c|c|c|c|c|c|c|c|c|}
\hline \multirow{2}{*}{\multicolumn{2}{|c|}{$\begin{array}{l}\text { Group } \\
\text { of dogs }\end{array}$}} & \multicolumn{13}{|c|}{$\begin{array}{l}\text { Time } \\
{[\mathrm{min}]}\end{array}$} \\
\hline & & 0 & 10 & 20 & 30 & 40 & 50 & 60 & 70 & 80 & 90 & 100 & 110 & 120 \\
\hline \multirow[b]{2}{*}{$\mathbf{T}$} & $x$ & 92.7 & 98.0 & 93.8 & 89.5 & 88.3 & 84.8 & 83.5 & 90.0 & 90.3 & 90.3 & 92.3 & 88.8 & 90.3 \\
\hline & SD & 8.1 & 13.6 & 11.2 & 6.2 & 6.7 & 5.6 & 7.9 & 15.1 & 12.3 & 11.7 & 9.3 & 5.3 & 3.9 \\
\hline \multirow[b]{2}{*}{ B } & $x$ & 89.0 & 94.2 & 87.2 & 82.0 & 71.7 & 78.7 & 75.8 & 74.0 & 86.5 & 79.2 & 75.3 & 86.8 & 76.5 \\
\hline & SD & 27.7 & 17.6 & 13.7 & 11.1 & 18.2 & 17.1 & 20.1 & 13.8 & 17.1 & 14.4 & 18.4 & 13.3 & 15.4 \\
\hline
\end{tabular}

Table 2. Changes in the mean heart rate in the groups of dogs (mean \pm SD)

\begin{tabular}{|c|c|c|c|c|c|c|c|c|c|c|c|c|c|c|}
\hline \multirow{2}{*}{$\begin{array}{l}\text { Group } \\
\text { of dogs }\end{array}$} & & \multicolumn{13}{|c|}{$\begin{array}{l}\text { Time } \\
\text { [min] }\end{array}$} \\
\hline & & 0 & 0 & 20 & 30 & 40 & 50 & 60 & 70 & 80 & 90 & 100 & 110 & 120 \\
\hline \multirow[b]{2}{*}{$\mathbf{T}$} & $x$ & 64.5 & 89 & 79 & 75.7 & 75 & 74.7 & 75.3 & 72.7 & 75.2 & 74 & 70.3 & 71.3 & 71.3 \\
\hline & SD & 14.6 & 43.2 & 25.9 & 17.7 & 10.8 & 7 & 6.1 & 12.2 & 12.1 & 13.1 & 7.8 & 7.4 & 7.9 \\
\hline \multirow[b]{2}{*}{ B } & $x$ & 68.5 & 75 & 86.8 & 78.7 & 71.3 & 74.7 & 72.5 & 71.2 & 82 & 74.8 & 79.3 & 66.8 & 64.2 \\
\hline & SD & 10.3 & 19.7 & 45.9 & 25 & 13.5 & 12.1 & 8.8 & 9.6 & 32.1 & 22.4 & 16.6 & 11.1 & 12.4 \\
\hline
\end{tabular}


Table 3. Changes in the respiratory rate in the groups of dogs (mean \pm SD)

\begin{tabular}{|c|c|c|c|c|c|c|c|c|c|c|c|c|c|c|}
\hline \multirow{2}{*}{$\begin{array}{l}\text { Group } \\
\text { of dogs }\end{array}$} & & \multicolumn{13}{|c|}{$\begin{array}{l}\text { Time } \\
\text { [min] }\end{array}$} \\
\hline & & 0 & 10 & 20 & 30 & 40 & 50 & 60 & 70 & 80 & 90 & 100 & 110 & 120 \\
\hline \multirow[b]{2}{*}{${ }^{*} \mathbf{T}$} & $x$ & 14.7 & 11.7 & 14.2 & 14.7 & 14.5 & 15.8 & 15.7 & 16.3 & 18.8 & 15.8 & 16.2 & 16.2 & 17.0 \\
\hline & SD & 4.8 & 3.7 & 5.2 & 5.9 & 5.0 & 3.9 & 5.4 & 6.9 & 6.2 & 6.9 & 6.0 & 6.0 & 5.8 \\
\hline \multirow[b]{2}{*}{ B } & $x$ & 15.2 & 16.0 & 15.3 & 15.8 & 29.3 & 25.2 & 28.2 & 23.8 & 26.0 & 21.5 & 22.3 & 22.7 & 26.3 \\
\hline & SD & 12.6 & 12.5 & 9.5 & 10.0 & 33.8 & 30.3 & 38.0 & 24.8 & 29.4 & 20.4 & 21.1 & 23.6 & 29.6 \\
\hline
\end{tabular}

* - Statistically significant differences between the groups $(P<0.001)$

Table 4. Changes in pain response in the groups of dogs (mean \pm SD)

\begin{tabular}{|c|c|c|c|c|c|c|c|c|c|c|c|c|c|c|}
\hline \multirow{2}{*}{$\begin{array}{l}\text { Groups } \\
\text { of dogs }\end{array}$} & & \multicolumn{13}{|c|}{$\begin{array}{l}\text { Time } \\
\text { [min] }\end{array}$} \\
\hline & & 0 & 10 & 20 & 30 & 40 & 50 & 60 & 70 & 80 & 90 & 100 & 110 & 120 \\
\hline \multirow{3}{*}{$* \mathbf{T}$} & $x$ & 1 & 1 & 1 & 1 & 1.3 & 1.3 & 1.5 & 1.5 & 1.8 & 1.7 & 1.2 & 1.2 & 1.8 \\
\hline & SD & 0 & 0 & 0 & 0 & 0.5 & 0.5 & 0.5 & 0.5 & 0.8 & 0.8 & 0.4 & 0.4 & 0.4 \\
\hline & $x$ & 1.3 & 1.8 & 1.8 & 1.8 & 2.2 & 2.2 & 2.2 & 2.2 & 2.0 & 2.2 & 2.2 & 2.0 & 2.8 \\
\hline B & SD & 0.5 & 0.4 & 0.4 & 0.4 & 0.4 & 0.4 & 0.4 & 0.4 & 0 & 0.4 & 0.4 & 0.0 & 0.4 \\
\hline
\end{tabular}

* - Statistically significant differences between the groups $(P<0.001)$

However, this result was obtained using atropine at a dose of $0.01 \mathrm{mg} \cdot \mathrm{kg}^{-1} \mathrm{IV}$ in four patients (40\%) of the group $\mathrm{B}$ with the aim to correct the developing bradycardia. In two dogs, it was necessary to apply it two times and in another two, three times during anaesthesia. In dogs of the $\mathrm{T}$ group, bradycardia occurred in one patient immediately after propofol induction. A single dose of atropine adjusted the heart rate for the rest of the anaesthesia. A significant difference was confirmed between the $\mathrm{T}$ and $B$ groups $(P<0.05)$ in relation to the frequency of the use of atropine. In three dogs in the $\mathrm{B}$ group, the tachypnoea ranging from $45-120$ breaths per minute were observed between buprenorphine administration and sedation. During TIVA, these dogs showed also tachypnoeic breathing of the costal type in the range of $28-132$ breaths per minute. Other dogs in this group had a tendency for bradypnoea with a respiratory rate in the range of $7-9$ breaths per min- ute. The statistical analysis between the average respiratory rate confirmed significant differences between the groups $(\mathrm{P}<0.001$, Tab. 3). The SAT ranged from 87 to $98 \%$ with insignificantly lower saturation in the $\mathrm{B}$ group. The pain response showed better results in the $\mathrm{T}$ group, where during the first 30 minutes of anaesthesia, no pain responses were noted (Tab. 4). Statistically better analgesia was achieved in the $\mathrm{T}$ group $(\mathrm{P}<0.001)$. In the recovery period, the average time of the extubation was 10 minutes and 50 seconds in the $\mathrm{B}$ group and 13 minutes in the $\mathrm{T}$ group. Head lifting (17.3 vs. $18.5 \mathrm{~min}$.), sternal position (25 vs. $30.3 \mathrm{~min}$.) and walking (27.7 vs. $32.3 \mathrm{~min}$.) appeared sooner in the T group. The body temperature did not show any significant changes during the general anaesthesia. The recovery times have not been statistically significant between groups. 


\section{DISCUSSION}

The comparison of the perioperative analgesic effects of the two analgesics was the main reason of this study. Buprenorphine is regulated by the Drug Enforcement Agency, while tramadol is not. This was also one of the reasons to compare these two analgesics, to facilitate the administrative work. Buprenorphine in human anaesthesia plays a role in regional epidural anaesthesia and is not used as perioperative analgesia. Tramadol is a much weaker pain medication when compared to morphine; equally about 10:1. Studies have shown that tramadol does not cause the breathing problems. For pain moderate in severity, its effectiveness is equivalent to that of morphine, for severe pain, it is less effective than morphine [12].

Tramadol $\left(1 \mathrm{mg} \cdot \mathrm{kg}^{-1}\right)$, administered after the induction of anaesthesia, offered equivalent postoperative pain relief, and similar recovery times and postoperative patient controlled analgesia (PCA) morphine consumption compared with giving morphine $0.1 \mathrm{mg} \cdot \mathrm{kg}^{-1}$. These results also suggest that pre-surgical exposure to systemic opioid analgesia may not result in clinically significant benefits [15].

Tramadol was not found to be a suitable analgesic for use in human balanced anaesthesia, because of problems with increased intraoperative awareness [11].

Our experience with tramadol in balanced anaesthesia does not confirm this argument. The dogs in the T group had significantly better parameters of blood pressure, respiratory rate and analgesia in comparison with the $\mathrm{B}$ group. Some disadvantage seems to be, no sedative effect in the dose used. Buprenorphine produced overt sedation shortly after administration in some patient accompanied with tachypnea. Buprenorphine seems to have potentiating effect to xylazine, as $50 \%$ of the dogs were possible to intubate without propofol induction. It was not seen in the group $\mathrm{T}$, where intubation was possible following propofol induction. The dogs in the B group had significantly higher episodes of bradycardia, corrected by an anticholinergic.

A study comparing tramadol and buprenorphine in cancer pain, confirmed the better tolerance of tramadol than buprenorphine, which caused fewer and milder adverse reactions. Tramadol, although theoretically less potent, nevertheless brought about as much pain relief as buprenorphine. In conclusion, for this class of drug, tramadol provided an excellent balance between efficacy and tolerability, confirming preliminary studies [1]. The experi- mental study by Kögel et al. [6] did not confirm antinociception of tramadol in beagles explaining it as marginal amounts of the M1 metabolite of tramadol.

Our results found in balanced anaesthesia in dogs where tramadol was used, confirmed significantly better monitored parameters in comparison with the buprenorphine group.

Buprenorphine, in our study, has produced sufficient sedation, but the analgesic effect was inferior to tramadol as seen in our results. Taylor, Houlton [14] also found that buprenorphine produced more sedation than morphine in dogs and considered that this affected the analgesia assessment. Whereas, in general anaesthesia, there is a loss of consciousness, the sedative effect of analgesics does not play as important a role in pain assessment like in awake animals in the post-operative period. While in the T group, we did not find signs of pain, within the first 30 minutes in the B group some dogs reacted with increased heart and respiratory rates from the beginning of the anaesthesia. Studies in human medicine also state the significantly better analgesic effect of oral tramadol in human oncologic patients suffering from strong/unbearable pain $[1,4]$. The time of recovery did not differ significantly between the groups, taking approximately 30 minutes to stand up and walk. It can be concluded that balanced anaesthesia with tramadol achieved significantly better endpoints at a lower frequency of corrective interventions to maintain the observed parameters in physiological range.

\section{ACKNOWLEDGEMENTS}

This study was supported by Scientific Grant Agency of Ministry of Education of the Slovak Republic and Slovak Academy of Sciences No. 1/0212/12.

\section{REFERENCES}

1. Bono, A. V., Cuffari, S., 1997: Effectiveness and tolerance of tramadol in cancer pain. A comparative study with respect to buprenorphine. Drugs, 53 Suppl. 2, 40-49.

2. Budd, K., Raffa, R. B., 2005: Buprenorphine - The unique opioid analgesic. Georg Thieme Verlag, Stuttgart, 3-21.

3. Brayfield, A., 2013: “Tramadol Hydrochloride”. Martindale: The Complete Drug Reference. Pharmaceutical Press. Retrieved April 5th, 2014, https://en.wikipedia.org/wiki/Tramadol. 
4. Brema, F., Pastorino, G., Martini, M.C., Gottlieb, A., Luzzani, M., Libretti, A., Sacca, L., Gigolari, S., 1996: Oral tramadol and buprenorphine in tumour pain. An Italian multicentre trial. Int. J. Clin. Pharmacol., 16, 109-116.

5. Duthie. D. J. R., 1998: Remifentanil and tramadol: recent advances in opioid pharmacology. Br. J. Anaesth., 81, 51-57.

6. Kögel, B., Terlinden, R., Schneider, J., 2014: Characterisation of tramadol, morphine and tapentadol in an acute pain model in Beagle dogs. Vet. Anaesth. Analg., 41, 297-304.

7. Mastrocinque, S., Fantoni, D. T., 2003: A comparison of preoperative tramadol and morphine for the control of early postoperative pain in canine ovariohysterectomy. Vet. Anaesth. Analg., 30, 220-228.

8. Moody, D.E., Fang Lin, S.N., Weyant, D.M., Strom, S. C., Omiecinski, C. J., 2009: Effect of Rifampin and Nelfinavir on the metabolism of methadone and buprenorphine in primary cultures of human hepatocytes. Drug Metab. Dispos., 37, 23232329.

9. Paul-Murphy, J.R., Brunson, D.B., Miletic, V., 1999: Analgesic effects of butorphanol and buprenorphine in conscious African grey parrots (Psittacus erithacus and Psittacus erithacus timneh). Am. J. Vet. Res., 60, 1218-1221.
10. Reimann, W., Schneider, F., 1998: Induction of 5-hydroxytryptamine release by tramadol, fenfluramine and reserpine. European Journal of Pharmacology, 349, 199-203.

11. Rhoda Lee, C., McTavish, D., Sorkin, E. M., 1993: Tramadol. Drugs, 46, Suppl. 2, 313-340.

12. Rossi, S., 2013: Australian Medicines Handbook. 2013 edn.. The Australian Medicines Handbook Unit Trust, Adelaide, $965 \mathrm{pp}$.

13. Roughan, J.V., Flecknell, P.A., 2002: Buprenorphine: a reappraisal of its antinociceptive effects and therapeutic use in alleviating post-operative pain in animals. Lab. Anim., 36, 322-343.

14. Taylor, P. M., Houlton, J.E.F., 1984: Postoperative analgesia in the dog - a comparison of morphine, buprenorphine and pentazocine. J. Small Anim. Pract., 25, 437-451.

15. Unlugenc, H., Ozalevli, M., Gunes, Y., Guler, T., Isik, G., 2003: Pre-emptive analgesic efficacy of tramadol compared with morphine after major abdominal surgery. Br. J. Anaesth., 91, 209-213.

Received November 25, 2015 